\title{
Laboratory simulation of heavy-ion cosmic-ray interaction with condensed $\mathrm{CO}$
}

\author{
E. Seperuelo Duarte ${ }^{1,2,3}$, A. Domaracka ${ }^{1}$, P. Boduch ${ }^{1}$, H. Rothard ${ }^{1}$, E. Dartois ${ }^{4}$, and E. F. da Silveira ${ }^{2}$ \\ ${ }^{1}$ Centre de Recherche sur les Ions, les Matériaux et la Photonique (CEA/CNRS/ENSICAEN/Université de Caen-Basse Normandie), \\ CIMAP - CIRIL - Ganil, Boulevard Henri Becquerel, BP 5133, 14070 Caen Cedex 05, France \\ e-mail: esduarte@gmail.com \\ 2 Physics Department, Pontifícia Universidade Católica, Rua Marquês de S. Vicente 225, 22453-900 Rio de Janeiro, Brazil \\ 3 Grupo de Física e Astronomia - CEFET/Química de Nilópolis, R. Lúcio Tavares 1045, Centro, 26530-060, Nilópolis, Brazil \\ ${ }^{4}$ Institut d'Astrophysique Spatiale, Astrochimie Expérimentale, UMR-8617 Université Paris-Sud, bâtiment 121, 91405 Orsay, France
}

Received 16 July 2009 / Accepted 14 January 2010

\section{ABSTRACT}

\begin{abstract}
Context. Within dense interstellar clouds, from their periphery to regions deep inside, ice mantles on dust grains are exposed to cosmic-ray irradiation. Various swift ions contribute from protons to iron in the $\mathrm{keV}$ to $\mathrm{TeV}$ energy range. Observations show that in some lines of sight condensed CO molecules are an important component of the ice.

Aims. We irradiate $\mathrm{CO}$ ices with $\mathrm{Ni}$ ions of relatively high energy (50 and $537 \mathrm{MeV}$ ) to simulate the effects produced by fast heavy cosmic-ray ions in interstellar grain mantles.

Methods. CO gas is condensed on a CsI substrate at $13 \mathrm{~K}$ and irradiated by $50 \mathrm{MeV}^{58} \mathrm{Ni}^{13+}$ and $537 \mathrm{MeV}^{64} \mathrm{Ni}^{24+}$ ions up to a final fluence of $\approx 1 \times 10^{13} \mathrm{~cm}^{-2}$, at a flux of $1 \times 10^{9} \mathrm{~cm}^{-2} \mathrm{~s}^{-1}$. The sputtering yields, the destruction rate of CO, and the rate of formation of new molecular species are measured in situ by Fourier transform infrared spectroscopy (FTIR).

Results. The measured $\mathrm{CO}$ destruction cross-sections and sputtering yields induced by Ni ions are, respectively, (i) for $50 \mathrm{MeV}$, $\sigma_{\mathrm{d}}=1.0 \times 10^{-13} \mathrm{~cm}^{2}$ and $Y=7 \times 10^{4}$ molecules/impact; (ii) for $537 \mathrm{MeV}, \sigma_{\mathrm{d}}=3.0 \times 10^{-14} \mathrm{~cm}^{2}$ and $Y=5.85 \times 10^{4}$ molecules/impact. Based on the present and previous results, the desorption rates induced by $\mathrm{H}, \mathrm{Ni}$, and $\mathrm{Fe}$ ions are estimated for a wide range of energies. The contribution of the heavy ions is found to dominate over that of protons in the interstellar medium.
\end{abstract}

Key words. astrochemistry - methods: laboratory - circumstellar matter - ISM: clouds - ISM: molecules

\section{Introduction}

Carbon monoxide is present in many astrophysical environments such as dense clouds and protoplanetary disks (e.g, Eiroa \& Hodapp 1989; Tielens et al. 1991; Whittet \& Duley 1991; Chiar et al. 1995; Elsila et al. 1997; Pontoppidan et al. 2003; Gibb et al. 2004; Dartois 2005; Bergin et al. 2006). CO has been observed in the gas phase as well as a condensed gas on dust grains. The abundance ratio of these two phases depends on the position of the grain in the cloud. At the cloud edge, because of the ambient interstellar radiation field, $\mathrm{CO}$ is predominantly in the gas phase (Shen et al. 2004). The external UV radiation cannot penetrate deeply into protoplanetary disks and dense clouds. Inside these objects, temperatures as low as $10 \mathrm{~K}$ may occur and $\mathrm{CO}$ molecules are expected to be present as ice on the grain mantles. According to estimations, the timescale to condense molecules $\left(\sim 10^{9} / n_{\mathrm{H}}\right.$ years; Watson 1975 ; Whittet 1992$)$ is shorter than the estimated age of the cloud. However, the observation of molecules in the gas phase suggests the existence of a non-thermal desorption mechanism. As cosmic-rays are the only energetic particles capable of penetrating even the most shielded regions, different non-thermal desorption mechanisms involving these particles have been proposed in the literature: photodesorption by UV photons induced by cosmic rays (cosmic ray photodesorption; Prasad \& Tarafdar 1983), collisional desorption by cosmic rays (sputtering), and the desorption by grain heating induced by cosmic rays (classical evaporation; Willacy \& Millar 1998). Öberg et al. (2007) proposed that cosmic ray photodesorption is comparable to the spot heating (desorption induced by a hot region at the ice surface created by cosmic ray impact) in the interior of the cloud.

A number of experimental studies involving chemical modifications of condensed carbon monoxide induced by different kinds of irradiation have been performed. Most of the experiments have included protons with energies ranging from 0.2 to $2 \mathrm{MeV}$ (Baird 1972; Gerakines \& Moore 2001; Trottier \& Brooks 2004; Loeffler et al. 2005; Palumbo et al. 2008) and 10.2 eV Lyman- $\alpha$ photons (Gerakines et al. 1996; Gerakines \& Moore 2001; Cottin et al. 2003; Loeffler et al. 2005). Jamieson et al. (2006) irradiated a CO sample with energetic electrons $(5 \mathrm{keV})$. In all cases, infrared spectroscopy was used to probe modifications induced in the ice. Moreover, carbon monoxide ice has also been bombarded with noble gas ions (Harning et al. 1984; Chisey et al. 1986) and Cf fission fragments (Farenzena et al. 2006; Ponciano et al. 2006). In these cases, mass spectrometry was employed to analyze the reaction products.

There is a clear lack of information about the effects induced by the heavy-ion component of cosmic-rays in the electronic-energy-loss regime. Irradiation of $\mathrm{CO}_{2}$ and mixed ices $\left(\mathrm{NH}_{3}: \mathrm{H}_{2} \mathrm{O}: \mathrm{CO}\right.$ and $\left.\mathrm{H}_{2} \mathrm{O}: \mathrm{NH}_{3}\right)$ by $\mathrm{Ni}$ ions was studied by Seperuelo Duarte et al. (2009) and Pilling et al. (2010). The aim of our present work was to extend these measurements by simulating the astrophysical environment where ice grain mantles deep inside dense regions are subject to heavy-ion cosmic-ray irradiation. We irradiated condensed $\mathrm{CO}$ with $50 \mathrm{MeV}^{58} \mathrm{Ni}^{13+}$ and $537 \mathrm{MeV}{ }^{64} \mathrm{Ni}^{24+}$ ion beams, and analyzed the products using 


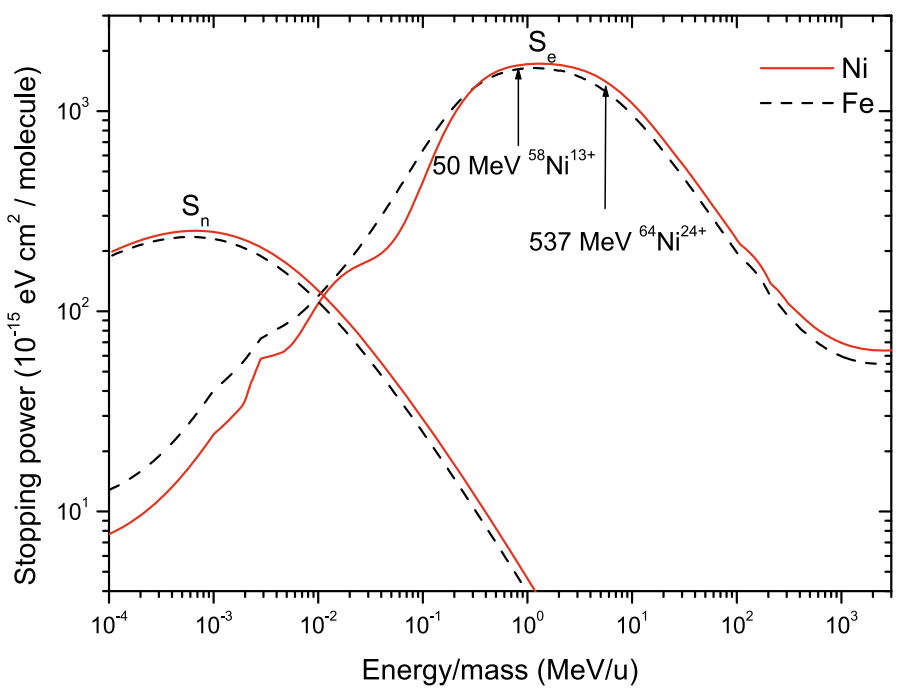

Fig. 1. Ni and Fe electronic $\left(S_{\mathrm{e}}\right)$ and nuclear $\left(S_{\mathrm{n}}\right)$ stopping power calculated by SRIM (Ziegler \& Biersack 2006) for condensed CO film. Arrows show the conditions of the current experiment.

Fourier transform infrared spectroscopy (FTIR). The physics and chemistry induced by nickel ions are similar to those induced by other heavy ions (such as iron, one of the most abundant species) since their electronic stopping power (Fig. 1) and nuclear track structure within the ice are nearly identical.

\section{Experimental}

The experimental apparatus consists of three parts: the analysis chamber, the beam line, and the deposition system. The analysis chamber is inserted in a FTIR spectrometer. A CsI substrate is situated at the center of the chamber (Fig. 2) under a residual gas pressure of $2 \times 10^{-8} \mathrm{mbar}$; it is in thermal contact with a cold finger cooled by a closed-cycle helium cryostat at a temperature of $13 \mathrm{~K}$. The deposition system consists of: a pre-chamber, where the gas is prepared; a micro-valve to control the deposition flux; and a tube that connects the pre-chamber to the analysis chamber.

The ice film was produced by gas condensation onto the cold substrate. Infrared spectra in the $5000-600 \mathrm{~cm}^{-1}(2-16.7 \mu \mathrm{m})$ region are acquired using a Nicolet FTIR spectrometer (Magna $550)$ with a spectral resolution of $1 \mathrm{~cm}^{-1}$. Since the main isotope transition is optically thick, the $\mathrm{CO}$ column density does not exhibit a linear relation with band area of the $v_{1}$ fundamental vibration at $2138 \mathrm{~cm}^{-1}$. Therefore, the ${ }^{13} \mathrm{CO}$ peak at $2092 \mathrm{~cm}^{-1}\left(A=1.3 \times 10^{-17} \mathrm{~cm} /\right.$ molecule; Gerakines et al. 1995) was used to estimate the $\mathrm{CO}$ column density $\left({ }^{12} \mathrm{CO} \approx\right.$ $\left.90 \times{ }^{13} \mathrm{CO}\right)$. For $50 \mathrm{MeV} \mathrm{Ni}$ ions, the initial column density was $1.6 \times 10^{18}$ molecules $/ \mathrm{cm}^{2}$. The ice thickness of $0.94 \mu \mathrm{m}$ was estimated using the initial column density, the $\mathrm{CO}$ molecular weight $\left(28 \mathrm{~g} / \mathrm{mol}\right.$ ), and the ice density of $0.81 \mathrm{~g} / \mathrm{cm}^{3}$ (Loeffler et al. 2005). In the case of $537 \mathrm{MeV}$ Ni projectiles, two different ice thickness were irradiated: $5.8 \times 10^{17}$ molecules $/ \mathrm{cm}^{2}(0.34 \mu \mathrm{m})$ and $1.04 \times 10^{18}$ molecules $/ \mathrm{cm}^{2}(0.60 \mu \mathrm{m})$.

The experimental set-up was mounted on the IRRSUD beam line for $50 \mathrm{MeV}{ }^{58} \mathrm{Ni}$ and on the SME beam line for $537 \mathrm{MeV}{ }^{64} \mathrm{Ni}$ at the heavy-ion accelerator GANIL (Grand Accélérateur National d'Ions Lourds). The ices were irradiated by $50 \mathrm{MeV}{ }^{58} \mathrm{Ni}^{13+}$ and $537 \mathrm{MeV}{ }^{64} \mathrm{Ni}^{24}$ ions at a flux rate of $1 \times 10^{9} \mathrm{~cm}^{-2} \mathrm{~s}^{-1}$. The final fluences were $1.1 \times 10^{13} \mathrm{~cm}^{-2}$ and $1.2 \times 10^{13} \mathrm{~cm}^{-2}$, respectively. More details about the

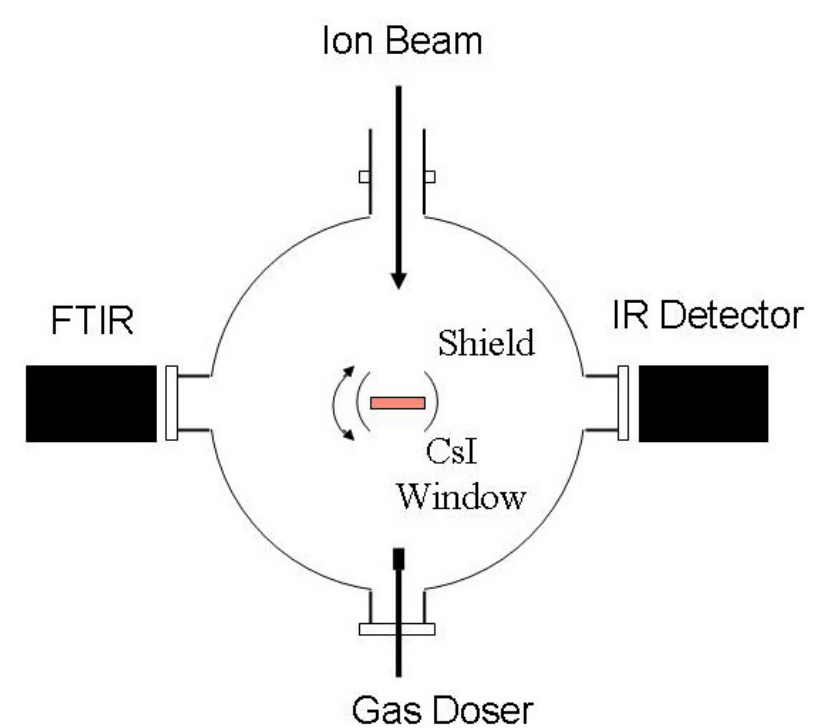

Fig. 2. A schematic representation of the experimental set-up. The ion beam impinges on the film ice deposited on a CsI substrate. A background spectrum is recorded at $13 \mathrm{~K}$ before gas deposition to correct the ice spectra.

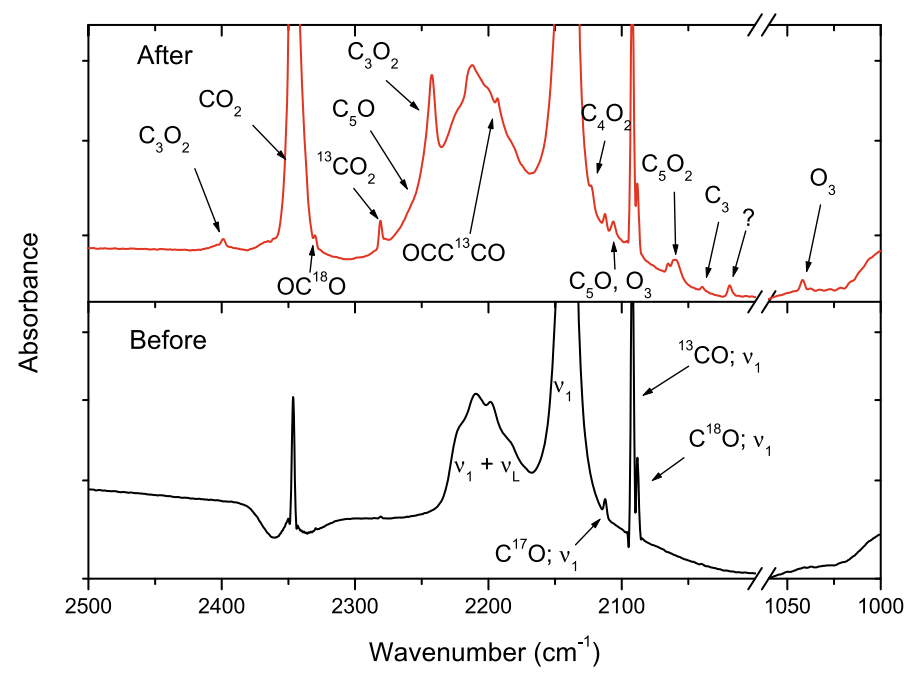

Fig. 3. Infrared spectrum of $\mathrm{CO}$ ice before and after $50 \mathrm{MeV}{ }^{58} \mathrm{Ni}^{11+}$ irradiation with a fluence of $1.0 \times 10^{12} \mathrm{~cm}^{-2}$.

experimental set-up can be found in Seperuelo Duarte et al. (2009). At these energies, the energy loss is caused by the electronic stopping power $\left(S_{\mathrm{e}}\right)$ (see Fig. 1) since these ions interact with $\mathrm{CO}$ ice mainly via inelastic collisions with target electrons leading to ionization and excitation of the target electrons. For $50 \mathrm{MeV}$ and $537 \mathrm{MeV} \mathrm{Ni}$ projectiles, the electronic stopping power values are $1690 \mathrm{eV} /\left(10^{15}\right.$ molecules $\left./ \mathrm{cm}^{2}\right)$ and $1180 \mathrm{eV} /\left(10^{15}\right.$ molecules $\left./ \mathrm{cm}^{2}\right)$, respectively.

\section{Results}

\subsection{Line identifications}

Table 1 shows the observed CO bands and a complete list of bands and associated molecules produced by heavy-ion irradiation. The same molecular species were observed at both 50 and $537 \mathrm{MeV}$. The $\mathrm{CO}_{2}$ molecule is a common product of $\mathrm{CO}$ radiolysis, photolysis, as well as $5 \mathrm{keV}$ electron irradiation 
Table 1. Peak position and assignments for irradiated CO; $A$ is the corresponding band strength.

\begin{tabular}{|c|c|c|c|c|}
\hline Position $\left(\mathrm{cm}^{-1}\right)$ & Molecule & Assignment & $A\left(10^{-17} \mathrm{~cm} /\right.$ molecule $)$ & Reference \\
\hline 4694 & $?$ & & & \\
\hline 4252 & $\mathrm{CO}$ & $2 v_{1}$ & & Jamieson et al. (2006) \\
\hline 3707 & $\mathrm{CO}_{2}$ & $v_{1}+v_{3}$ & & Gerakines et al. (1995) \\
\hline 3602 & $\mathrm{CO}_{2}$ & $2 v_{2}+v_{3}$ & & Gerakines et al. (1995) \\
\hline 3070 & $\mathrm{C}_{3} \mathrm{O}_{2}$ & $v_{2}+v_{3}$ & & Gerakines \& Moore (2001) \\
\hline 2399 & $\mathrm{C}_{3} \mathrm{O}_{2}$ & $v_{2}+v_{4}$ & & Gerakines \& Moore (2001) \\
\hline 2346 & $\mathrm{CO}_{2}$ & $v_{3}$ & 7.6 & Yamada \& Person (1964) \\
\hline 2330 & $\mathrm{OC}^{18} \mathrm{O}$ & $v_{3}$ & & Jamieson et al. (2006) \\
\hline 2281 & ${ }^{13} \mathrm{CO}_{2}$ & $v_{3}$ & & Gerakines et al. (1995) \\
\hline 2257 & $\mathrm{C}_{5} \mathrm{O}$ & & & Dibben et al. (2000) \\
\hline 2247 & $\mathrm{C}_{3} \mathrm{O}$ & $v_{1}$ & & Jamieson et al. (2006) \\
\hline 2242 & $\mathrm{C}_{3} \mathrm{O}_{2}$ & $v_{3}$ & 13 & Gerakines \& Moore (2001) \\
\hline 2209 & $\mathrm{CO}$ & $v_{1}+v_{L}$ & & Jamieson et al. (2006) \\
\hline 2193 & $\mathrm{C}_{3} \mathrm{O}_{2}$ & $v_{1}$ & & Jamieson et al. (2006) \\
\hline 2139 & $\mathrm{CO}$ & $v_{1}$ & 1.1 & Jiang et al. (1975) \\
\hline 2123 & $\mathrm{C}_{4} \mathrm{O}_{2}$ or $\mathrm{C}_{7} \mathrm{O}_{2}$ & $v_{2}$ & & Jamieson et al. (2006) \\
\hline 2112 & $\mathrm{C}^{17} \mathrm{O}$ & $v_{1}$ & & Palumbo et al. (2008) \\
\hline 2107 & $\mathrm{C}_{5} \mathrm{O}$ and $\mathrm{O}_{3}$ & $v_{2} ; v_{1}+v_{3}$ & & Jamieson et al. (2006); Bennet \& Kaiser (2005) \\
\hline 2092 & ${ }^{13} \mathrm{CO}$ & $v_{1}$ & & Gerakines et al. (1995) \\
\hline 2088 & $\mathrm{C}^{18} \mathrm{O}$ & $v_{1}$ & & Jamieson et al. (2006) \\
\hline 2074 & $?$ & & & Freivogel et al. (1996) \\
\hline 2071 & $?$ & & & \\
\hline 2070 & $?$ & & & \\
\hline 2065 & $?$ & & & Szczepanski et al. (1996) \\
\hline 2060 & $\mathrm{C}_{5} \mathrm{O}_{2}$ & $v_{3}$ & 7.4 & Jamieson et al. (2006) \\
\hline 2039 & $\mathrm{C}_{3}$ & $v_{3}$ & 13 & Jamieson et al. (2006) \\
\hline 2019 & $?$ & & & \\
\hline 1989 & $\mathrm{C}_{2} \mathrm{O}$ & $v_{1}$ & 2.4 & Jamieson et al. (2006) \\
\hline 1950 & $\mathrm{C}_{6}$ & & & Trottier \& Brooks \\
\hline 1915 & $\mathrm{C}_{4} \mathrm{O}$ & $v_{2}$ & & Jamieson et al. (2006) \\
\hline 1874 & $?$ & & & \\
\hline 1859 & $?$ & & & \\
\hline 1817 & $\mathrm{C}_{5} \mathrm{O}$ & $v_{3}$ & 6.2 & Jamieson et al. (2006) \\
\hline 1303 & ? & & & \\
\hline 1041 & $\mathrm{O}_{3}$ & & 1.53 & Bennet \& Kaiser (2005) \\
\hline 879 & $?$ & & & \\
\hline 659 & $\mathrm{CO}_{2}$ & $v_{2}$ & & \\
\hline
\end{tabular}

(Loeffler et al. 2005; Jamieson et al. 2006; Trottier \& Brooks 2004). In the present work, carbon dioxide is identified by means of its strong $v_{3}$ and $v_{2}$ fundamental lines at $2346 \mathrm{~cm}^{-1}$ and $659 \mathrm{~cm}^{-1}$, respectively. Three others lines related to $\mathrm{CO}_{2}$ combination modes are also visible (see Table 1 ). The $v_{3}$ vibration of the ${ }^{13} \mathrm{CO}_{2}$ is also observed at $2281 \mathrm{~cm}^{-1}$ (Gerakines et al.1995).

The peak at $1988 \mathrm{~cm}^{-1}$ has been commonly attributed to the $\mathrm{C}_{2} \mathrm{O}$ molecule (Palumbo et al. 2008; Jamieson et al. 2006; Trottier \& Brooks 2004; Gerakines et al. 1996). Despite its simple formation reaction, this molecule has one of the lowest abundances of all detectable molecules in the present experiment. This means that $\mathrm{C}_{2} \mathrm{O}$ may be an intermediate step in the formation of other molecules, such as $\mathrm{C}_{3} \mathrm{O}$ and $\mathrm{C}_{3} \mathrm{O}_{2}$ (see in Sect. 4). In this experiment, $\mathrm{C}_{3} \mathrm{O}$ is observed through a small shoulder at $2247 \mathrm{~cm}^{-1}$ overlapped with an intense absorption line of $\mathrm{C}_{3} \mathrm{O}_{2}$ at $2242 \mathrm{~cm}^{-1}$ (Dibben et al. 2000; Gerakines \& Moore 2001).

A weak band at $2122 \mathrm{~cm}^{-1}$ rises at the beginning of the irradiation $\left(F=5 \times 10^{10} \mathrm{~cm}^{-2}\right)$. Two different assignments were suggested in the literature: $v_{2}$ vibration of the $\mathrm{C}_{4} \mathrm{O}_{2}$ molecule (Jamieson et al. 2006) and $v_{6}$ vibration of the $\mathrm{C}_{7} \mathrm{O}_{2}$ molecule (Trottier \& Brooks 2004). Since no other vibration mode produced by these molecules is present in the acquired spectra, it is not possible to confirm whether one or both molecular species contribute to this vibration.
Three different assignments were proposed for the band at $2107 \mathrm{~cm}^{-1}$ : the combination mode $v_{1}+v_{3}$ of $\mathrm{O}_{3}$ (Bennet \& Kaiser 2005); the $v_{2}$ vibration of the $\mathrm{C}_{5} \mathrm{O}$ molecule (Jamieson et al. 2006); and the $v_{1}-v_{L}$ combination band of the $\mathrm{C}_{3} \mathrm{O}_{2}$ molecule (Gerakines \& Moore 2001). The combination mode of $\mathrm{C}_{3} \mathrm{O}_{2}$ can be excluded since this molecule is highly diluted in the $\mathrm{CO}$ ice. In these circumstances, the lattice mode should not be active. The $\mathrm{C}_{5} \mathrm{O}$ molecule may contribute to the $2107 \mathrm{~cm}^{-1}$ band, because additional vibrations at $1817 \mathrm{~cm}^{-1}$ and $2257 \mathrm{~cm}^{-1}$ (Jamieson et al. 2006; Dibben et al. 2000) are observed in the current experiment. The $\mathrm{O}_{3}$ molecule is clearly identified by detection of its $v_{3}$ vibration at $1041 \mathrm{~cm}^{-1}$ (Bennet \& Kaiser 2005), showing that the abundance of oxygen atoms in the ice should be high. Therefore, the $2107 \mathrm{~cm}^{-1}$ band is assigned to both molecules.

Palumbo et al. (2008) and Jamieson et al. (2006) observed a small band at $\approx 2065 \mathrm{~cm}^{-1}$. In the current experiment, this band was also observed on top of a more intense band at $\approx 2060 \mathrm{~cm}^{-1}$, which was attributed to the $v_{5}$ vibration of the $\mathrm{C}_{5} \mathrm{O}_{2}$ molecule (Palumbo et al. 2008; Jamieson et al. 2006; Trottier \& Brooks 2004).

The $\mathrm{C}_{3}$ molecule was identified by the $2039 \mathrm{~cm}^{-1}$ line (Weltner et al. 1964; Jacox \& Milligan 1974; Cermak et al. 1998). In the current experiment, this peak rises early $(F=$ $\left.1 \times 10^{10} \mathrm{~cm}^{-2}\right)$ in the spectrum and disappears at high fluences 
$\left(F=8.75 \times 10^{12} \mathrm{~cm}^{-2}\right)$ where the bands for complex molecules start to be come visible. This suggests that tricarbon molecules are precursors to the formation of long-chain carbon molecules. At a fluence of $5 \times 10^{10} \mathrm{~cm}^{-2}$, a peak rises at $1950 \mathrm{~cm}^{-1}$ and disappears at $5 \times 10^{12} \mathrm{~cm}^{-2}$. This line was attributed to a vibration of the $\mathrm{C}_{6}$ molecule (Trottier \& Brooks 2004). Finally, a peak at $2074 \mathrm{~cm}^{-1}$ appears in the spectrum corresponding to high fluences $\left(F=5 \times 10^{12} \mathrm{~cm}^{-2}\right)$. There are many possible species that may absorb this wavenumber. Among them, $\mathrm{C}_{10}$ seems to be the most probable molecule to assign (Freivogel et al. 1997). This indicates that there has been an evolution of the long-chain carbon species formation from $\mathrm{C}_{3}$ to $\mathrm{C}_{10}$. However, further investigation is required to confirm this result. The peak at $1915 \mathrm{~cm}^{-1}$ rises at medium fluences $\left(F=1 \times 10^{11} \mathrm{~cm}^{-2}\right)$ and disappears soon after $(F=$ $\left.5 \times 10^{11} \mathrm{~cm}^{-2}\right)$. Among the many possibilities of assignment, $\mathrm{C}_{4} \mathrm{O}$ is the most probable molecule responsible for this absorption (Palumbo et al. 2008; Jamieson et al. 2006; Trottier \& Brooks 2004).

\subsection{Quantitative analysis}

Figure 4 shows the evolution of $\mathrm{CO}$ column density as a function of $50 \mathrm{MeV}$ and $537 \mathrm{MeV}$ nickel ions for all studied ices. The decreasing CO column density is related to the formation of other species (via CO dissociation) and to the sputtering induced by heavy ions. To analyze these effects, the data were fitted by Eq. (1) (Seperuelo Duarte et al. 2009) with two sets of parameters representing the sputtering and the dissociation, which are the processes given by:

$N=N_{0} \exp \left(-\sigma_{\mathrm{d}} F\right)-Y / \sigma_{\mathrm{d}}\left(1-\exp \left(-\sigma_{\mathrm{d}} F\right)\right)$,

where $N_{0}$ is the initial column density, $\sigma_{\mathrm{d}}$ is the destructioncross section, and $Y$ is the sputtering yield. Therefore, IR spectrometry does not directly measure the sputtering yield but this can be obtained by analyzing the evolution of CO column density as a function of fluence. The obtained values of destructioncross sections and sputtering yields are presented in Table 2 . The experiments performed with $537 \mathrm{MeV} \mathrm{Ni}$ ions for two different initial column densities confirmed that neither destruction cross section nor sputtering yield depend on thickness, because their estimated values are the same within the error-bars. This is not the case for very thin ices, where the influence of substrate and radiolysis products has to be taken into account. In future studies, the average values $\sigma_{\mathrm{d}}=3 \times 10^{-14} \mathrm{~cm}^{2}$ and $Y=$ $5.85 \times 10^{4}$ molecules/ion will be used. These values are related to the lower energy transferred by the $537 \mathrm{MeV}$ projectile. The obtained sputtering yield values, for the two $\mathrm{Ni}$ ion energies, are in close agreement with the predictions of Brown et al. (1984), who found a quadratic relation between sputtering yield and electronic stopping power $\left(Y \sim S_{\mathrm{e}}^{2}\right)$. We note that the sputtering yield infers the average number of $\mathrm{CO}$ molecules removed per impact. Brown et al. (1984) observed using quadrupole mass spectrometry that the $\mathrm{CO}$ molecules are the overwhelming dominant ejected species from ice. The emission of neutral clusters is also expected to produce a high yield, as discussed by Ponciano et al. (2008) for the condensed $\mathrm{O}_{2}$ target. The sputtering of ion species from $\mathrm{CO}$ bombarded by $65 \mathrm{MeV}$ heavy-ions was measured by Farenzena et al. (2006) using time-of-flight mass spectrometry, $\mathrm{CO}^{+}$being one of the most abundant secondary ion. Defining the radiochemical yield as $G=100 \sigma_{\mathrm{d}} / S_{\mathrm{e}}$, the values obtained for the 50 and $537 \mathrm{MeV}$ Ni ions are $G=5.9$ molecules/(100 eV) and $G=2.5$ molecules/(100 eV), respectively.

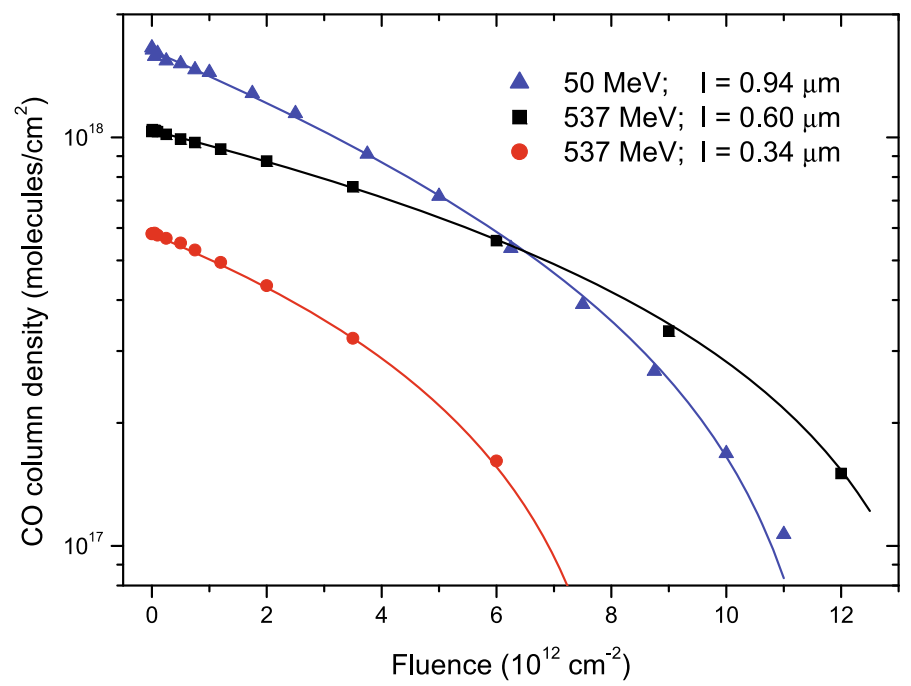

Fig. 4. Column density of $\mathrm{CO}$ molecules irradiated with $50 \mathrm{MeV}$ and $537 \mathrm{MeV} \mathrm{Ni}$ ions as a function of fluence. The CO data are fitted by Eq. (1). The fitting results are presented in Table 2.

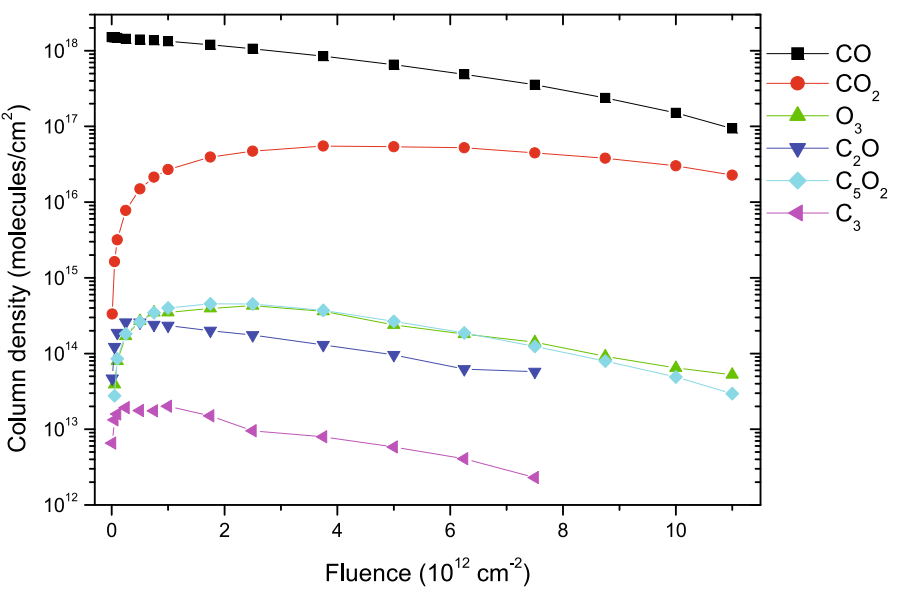

Fig. 5. Column density of $\mathrm{CO}$ and molecules produced as a function of fluence of $50 \mathrm{MeV} \mathrm{Ni}$ ions.

Figure 5 shows the evolution of the column density of species formed during irradiation by $50 \mathrm{MeV} \mathrm{Ni}$ ions as a function of fluence. $\mathrm{CO}_{2}$ is the most abundant observable molecule formed in the ice. The abundance of some molecules $\left(\mathrm{C}_{2} \mathrm{O}\right.$ and $\mathrm{C}_{3}$ ) have decreased to below the limit of detection at intermediate values of fluence.

The formation-cross sections of each molecular species were obtained from the slope of low fluence measurements, before the relative contribution of sputtering became important. Table 3 presents the formation cross sections and the corresponding radiochemical yields.

\section{Discussion}

\subsection{Comparison with $\mathrm{CO}_{2}$}

The description of the reaction dynamics generated within a condensed solid irradiated by fast $\mathrm{Ni}$ ions is a difficult task. The energy deposited in matter is high enough to allow the existence of many different pathways to produce molecules. In the projectile track, multiple ionizations generate a flux of electrons that produce additional ionization, excitation, and/or dissociation. A complete description of these chemical reactions is beyond the scope of the present work. However, by comparing our present 
Table 2. Destruction cross-sections and sputtering yields obtained for CO experiments.

\begin{tabular}{llll}
\hline \hline $\begin{array}{l}\text { Projectile energy } \\
(\mathrm{MeV})\end{array}$ & $\begin{array}{l}\text { CO column density } \\
\left(10^{17} \text { molecules } / \mathrm{cm}^{2}\right)\end{array}$ & $\begin{array}{l}\text { Destruction cross-section } \\
\left(10^{-14} \mathrm{~cm}^{2}\right)\end{array}$ & $\begin{array}{l}\text { Sputtering yield } \\
\left(10^{4} \text { molecules/impact }\right)\end{array}$ \\
\hline 50 & 16.3 & $10.0 \pm 0.1$ & $7 \pm 1$ \\
537 & 5.8 & $3.5 \pm 1.0$ & $5.8 \pm 0.4$ \\
537 & 10.4 & $2.6 \pm 0.3$ & $5.9 \pm 0.2$ \\
\hline
\end{tabular}

$\mathrm{CO}$ results $(50 \mathrm{MeV})$ with those obtained for $\mathrm{CO}_{2}$ irradiated by a $46 \mathrm{MeV}$ Ni beam (Seperuelo Duarte et al. 2009), we can infer relevant information about the reactions occurring in the ice. These two samples have similar initial column densities and were irradiated by the same projectile with a very close energy. In the case of $\mathrm{CO}_{2}$ ice, only four new species were observed: $\mathrm{CO}, \mathrm{CO}_{3}, \mathrm{O}_{3}$, and $\mathrm{C}_{3}$. In the present work, for $\mathrm{CO}$ ice, at least 10 new molecular species were identified, such as carbon-chain oxides and long carbon-chains. This difference is attributed to the higher reactivity of $\mathrm{CO}$ molecular fragments with respect to those of $\mathrm{CO}_{2}$ just after the projectile interaction. The radiolysis products react preferentially with the most abundant species in the matrix, namely, $\mathrm{CO}$ molecules in the current experiment. Since $\mathrm{CO}_{2}$ is less reactive, it acts like a shielding cage preventing the formation of large molecules.

Another clue about chemical reactions could be obtained by analyzing the common products observed in both experiments: $\mathrm{C}_{3}$ and $\mathrm{O}_{3}$. The formation cross-section of the $\mathrm{O}_{3}$ molecule is one order of magnitude higher in the $\mathrm{CO}_{2}$ experiment, probably because two $\mathrm{CO}_{2}$ molecules react to form $\mathrm{CO}$ and $\mathrm{O}_{2}$ $\left(2 \mathrm{CO}_{2} \rightarrow 2 \mathrm{CO}+\mathrm{O}_{2}\right)$. In the case of $\mathrm{C}_{3}$ molecules, their low abundance in the $\mathrm{CO}_{2}$ experiment prevents the measurement of their formation-cross section. This can be understood since the main dissociation pathways in the $\mathrm{CO}_{2}$ experiment do not produce carbon atoms. In contrast, two $\mathrm{CO}$ dissociation pathways produce carbon atoms, which increases the abundance of $\mathrm{C}_{3}$.

A comparison between $\mathrm{CO}$ and $\mathrm{CO}_{2}$ ices bombarded by heavy ions and analyzed by mass spectrometry was discussed by Ponciano et al. (2006). For CO ice, they observed that a large quantity of unbound carbon is generated in the nuclear track $\left(\mathrm{CO}^{+}+\mathrm{CO} \rightarrow \mathrm{CO}_{2}+\mathrm{C}^{+}\right)$, which in turn produces carbon chains. For $\mathrm{CO}_{2}$ ice, carbon chains are not observed but, instead, the $\mathrm{CO}_{2}$ molecular dissociation liberates negative oxygen ions that in turn react with $\mathrm{CO}_{2}$ to produce $\mathrm{CO}_{3}^{-}$radicals. These findings are in perfect agreement with the present results.

\subsection{Comparison with other experiments}

Considering the $\mathrm{CO}$ radiolysis products from a qualitative point of view, the effects induced by nickel ions, protons $(200 \mathrm{keV}$, Loeffler et al. 2005; Palumbo et al. 2008; $800 \mathrm{keV}$ Gerakines \& Moore 2001; $2 \mathrm{MeV}$, Trottier \& Brooks 2004), photons (10.2 eV, Gerakines et al. 1996; Gerakines \& Moore 2001; Cottin et al. 2003; Loeffler et al. 2005), and electrons ( $5 \mathrm{keV}$, Jamieson et al. 2006) are all similar. However, a striking difference occurs when observing ozone production. Loeffler et al. (2005) did not observe ozone in a CO ice irradiated by $200 \mathrm{keV}$ protons. However, ozone was observed by Palumbo et al. (2008) using the same projectile with the same energy. In the current experiment, we agree with Palumbo et al. in observing the fundamental vibration of $\mathrm{O}_{3}$ molecules $\left(1041 \mathrm{~cm}^{-1}\right)$. This is experimental proof of an important production of oxygen atoms and molecules in the matrix $\left[\mathrm{O}_{3} / \mathrm{CO}\right] \sim 10^{-3}$. However, it is surprising that the production of ozone can occur without carbon trioxide formation, which had been observed during the condensed $\mathrm{CO}_{2}$ radiolysis and photolysis. An explanation could be that $\mathrm{CO}_{3}$ is readily destroyed when reacting with the $\mathrm{CO}$ matrix to produce $\mathrm{CO}_{2}$ molecules.

Table 3 compares the cross-sections and radiochemical yields $(G)$ calculated in the present experiment with published values. The negative $G$ values for $\mathrm{CO}$ obtained in the current experiment correspond to the destruction cross-sections quoted in Sect. 3.2. Although the destruction $G$ values estimated here are much higher than those for protons and photons, the formation $G$ values of the produced molecules are similar. For $\mathrm{CO}_{2}$ formation, the $G$ values obtained in the current experiment are much higher than those for protons and photons. On the other hand, for the $\mathrm{C}_{3} \mathrm{O}_{2}$ molecule, the $G$ value at $50 \mathrm{MeV}$ is lower than that for $800 \mathrm{keV}$ protons. It is interesting to note that the radiochemical yield of $537 \mathrm{MeV}$ ions is an order of magnitude higher than that for $50 \mathrm{MeV}$ ions. In the case of $\mathrm{Ni}$ ions, the formation $G$ for $\mathrm{CO}_{2}$ corresponds to $20 \%(50 \mathrm{MeV})$ and $60 \%(537 \mathrm{MeV})$ of the destruction $G$ value for CO. For protons, this ratio is about $80 \%$ (which means that with Ni beam more different species are produced).

\subsection{Astrophysical implications}

CO molecules are observed in the gas phase below sublimation temperatures meaning that desorption processes are active. Among the possible processes, three general mechanisms are proposed: thermal desorption, photon-induced desorption, and cosmic-ray-induced desorption. In this latter case, spot heating (from a thermal spike around the ion track), but also wholegrain-heating (depending on the size of the grains) can contribute (Bringa \& Johnson 2004). Thermal desorption and interstellar radiation field photodesorption are active essentially at the inner interfaces (close to a recently born star) and on the outer interfaces of the clouds (exposed to the interstellar radiation-field). In well protected extinct regions, where external UV photons do not penetrate, photodesorption can also take place because of cosmic-ray-induced secondary UV photons (e.g., Westley et al. 1995). Öberg et al. (2007) claimed that photodesorption dominates at the edge of dense clouds for small $(0.1 \mu \mathrm{m})$ and large grains (of a few microns) and becomes comparable to the spot heating desorption inside the cloud $\left(A_{\mathrm{v}}>15\right)$. Léger et al. (1985) estimated spot and impulsive (whole grain) heating desorption of about 70 molecules $/ \mathrm{cm}^{2} \mathrm{~s}$ by considering different heavy ions with $Z<28$, energies between 20 and $1000 \mathrm{MeV} /$ nucleon, and the abundances given by Young et al. (1981).

The results of the present work provide experimental insight into the understanding of desorption occurring in dense clouds via sputtering over the grain surface. The sputtering yield of $\mathrm{Ni}$ ions follows the proportionality to the square of the electronic stopping power $\left(Y \sim S_{\mathrm{e}}^{2}\right)$ found by Brown et al. (1984) (Fig. 6). This was used to estimate the desorption rate induced by heavyions from the grains in dense clouds.

By considering the $Y \sim S_{\mathrm{e}}^{2}$ relation and the electronic stopping powers calculated by SRIM for $\mathrm{Ni}, \mathrm{Fe}$, and $\mathrm{H}$ ions crossing 
A\&A 512, A71 (2010)

Table 3. Cross-sections and radiochemical yields for molecules identified in present experiment.

\begin{tabular}{|c|c|c|c|c|}
\hline Molecules & Projectile & $\sigma\left(10^{-15} \mathrm{~cm}^{2}\right)$ & $G$ (molecules $/ 100 \mathrm{eV})$ & Reference \\
\hline $\mathrm{CO}$ & $\begin{array}{l}50 \mathrm{MeV} \mathrm{Ni}^{13+} \\
537 \mathrm{MeV} \mathrm{Ni}^{24+} \\
200 \mathrm{keV} \mathrm{H}^{+} \\
10.2 \mathrm{eV} \text { photons } \\
>6 \mathrm{eV} \text { photons } \\
>6 \mathrm{eV} \text { photons }\end{array}$ & $\begin{array}{l}100 \\
30 \\
0.28 \\
0.0003 \\
<0.000001 \\
<0.00008 \\
\end{array}$ & $\begin{array}{l}-5.9 \\
-2.5 \\
-0.79\end{array}$ & $\begin{array}{l}\text { This work } \\
\text { This work } \\
\text { Loeffler et al. (2005) } \\
\text { Loeffler et al. (2005) } \\
\text { Cottin et al. (2003) } \\
\text { Gerakines et al. (1996) }\end{array}$ \\
\hline $\mathrm{CO}_{2}$ & $\begin{array}{l}50 \mathrm{MeV} \mathrm{Ni}^{13+} \\
537 \mathrm{MeV} \mathrm{Ni}^{24+} \\
200 \mathrm{keV} \mathrm{H}^{+} \\
800 \mathrm{keV} \mathrm{H}^{+} \\
10.2 \mathrm{eV} \text { photons } \\
10.2 \mathrm{eV} \text { photons } \\
>6 \mathrm{eV} \text { photons } \\
\end{array}$ & $\begin{array}{l}20 \\
18 \\
6 \\
0.017 \\
0.000013 \\
\end{array}$ & $\begin{array}{l}1.2 \\
1.5 \\
0.62 \\
0.25 \\
0.59 \\
0.9\end{array}$ & $\begin{array}{l}\text { This work } \\
\text { This work } \\
\text { Loeffler et al. (2005) } \\
\text { Gerakines \& Moore (2001) } \\
\text { Loeffler et al. (2005) } \\
\text { Gerakines \& Moore (2001) } \\
\text { Gerakines et al. (1996) }\end{array}$ \\
\hline $\mathrm{O}_{3}$ & $50 \mathrm{MeV} \mathrm{Ni}^{13+}$ & 0.3 & 0.018 & This work \\
\hline $\mathrm{C}_{3} \mathrm{O}_{2}$ & $\begin{array}{l}50 \mathrm{MeV} \mathrm{Ni}^{13+} \\
537 \mathrm{MeV} \mathrm{Ni}^{24+} \\
800 \mathrm{keV} \mathrm{H}^{+} \\
10.2 \mathrm{eV} \text { photons }\end{array}$ & $\begin{array}{l}3 \\
25\end{array}$ & $\begin{array}{l}0.18 \\
2.2 \\
0.24 \\
0.014 \\
\end{array}$ & $\begin{array}{l}\text { This work } \\
\text { This work } \\
\text { Gerakines \& Moore (2001) } \\
\text { Gerakines \& Moore (2001) }\end{array}$ \\
\hline $\mathrm{C}_{5} \mathrm{O}_{2}$ & $\begin{array}{l}50 \mathrm{MeV} \mathrm{Ni}^{13+} \\
537 \mathrm{MeV} \mathrm{Ni}^{24+}\end{array}$ & $\begin{array}{l}0.45 \\
0.23 \\
\end{array}$ & $\begin{array}{l}0.027 \\
0.02 \\
\end{array}$ & $\begin{array}{l}\text { This work } \\
\text { This work }\end{array}$ \\
\hline $\mathrm{C}_{2} \mathrm{O}$ & $50 \mathrm{MeV} \mathrm{Ni}^{13+}$ & 2 & 0.12 & This work \\
\hline $\mathrm{C}_{3}$ & $50 \mathrm{MeV} \mathrm{Ni}^{13+}$ & 0.15 & 0.0089 & This work \\
\hline
\end{tabular}

Notes. The presented value for $\mathrm{CO}$ molecules are destruction cross-sections, while for other molecules the formation cross-sections are given.

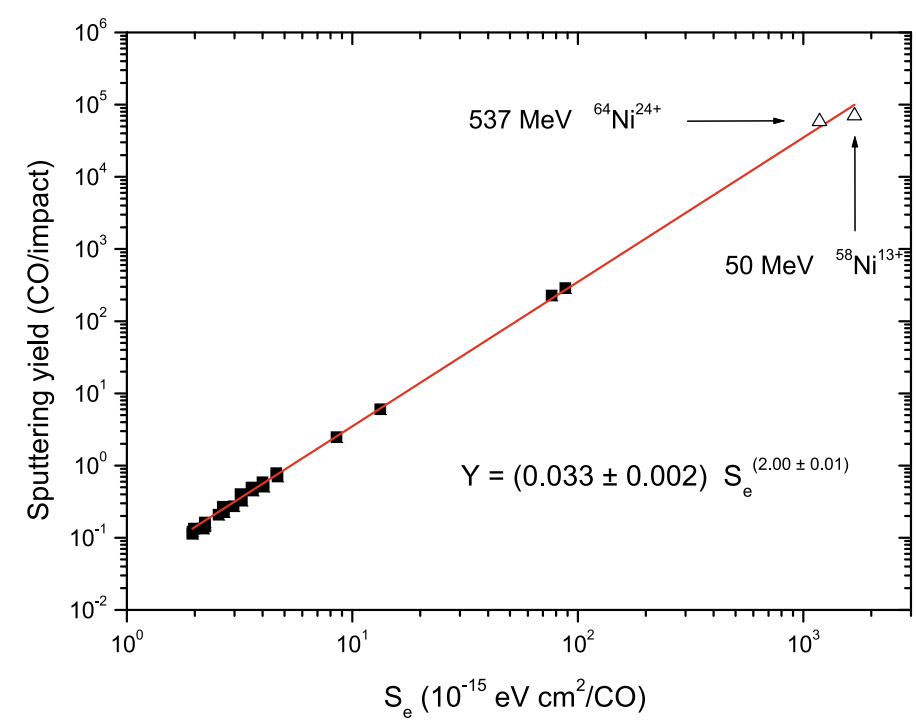

Fig. 6. Sputtering yield vs stopping power for $\mathrm{CO}$ ice. Full squares are the experimental points taken from Brown et al. (1984) and open triangles are present results for $\mathrm{Ni}$ ions.

a CO ice, the sputtering yield can be displayed as a function of the projectile energy (Fig. 7).

The cosmic ray abundance data were taken from Shen et al. (2004). The velocity distributions of heavy ions are very similar to those of protons (Simpson 1983) and the abundance ratios are $\mathrm{Fe} / \mathrm{H}=7.13 \times 10^{-4}$ (Shen et al. 2004) and $\mathrm{Ni} / \mathrm{Fe}=5.5 \times 10^{-2}$ (Karrer et al. 2007), respectively. This information allows us to estimate the desorption rates induced by $\mathrm{H}, \mathrm{Ni}$, and $\mathrm{Fe}$ ions as a function of projectile energy in the $5 \times 10^{-1}-1 \times 10^{4} \mathrm{MeV} / \mathrm{u}$ range (Fig. 8). The total desorption rate (integrated over the aforementioned energy region) is indicated at the bottom of the figure.

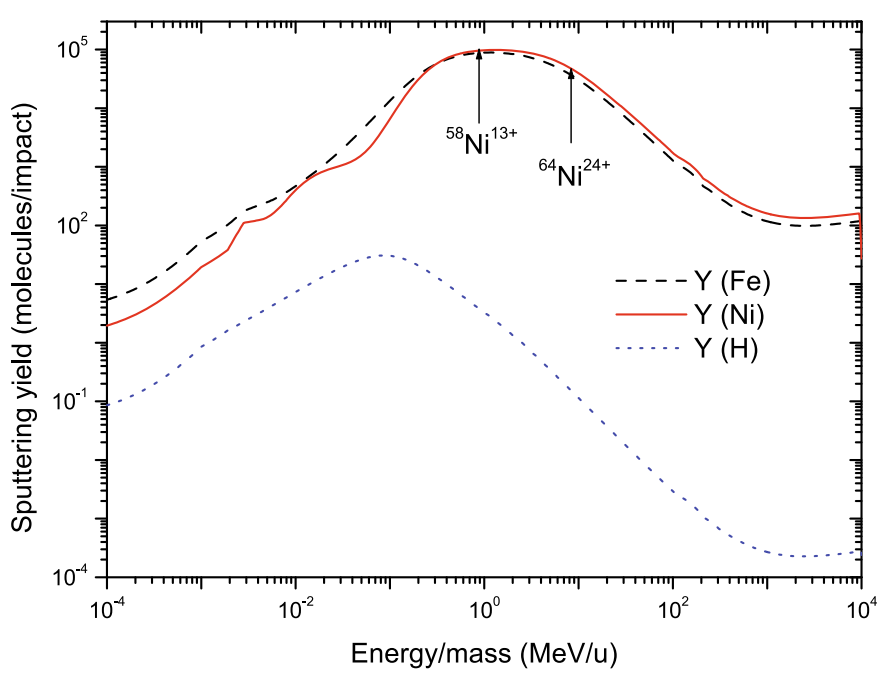

Fig. 7. Sputtering yield induced by $\mathrm{H}, \mathrm{Ni}$ and $\mathrm{Fe}$ ions as a function of their energy/mass.

The maximum value of total desorption rate is obtained for iron ions.

Figure 9 shows the comparison between photodesorption, spot heating, and sputtering as a function of visual extinction values $\left(A_{\mathrm{V}}\right)$ of dense clouds. Photodesorption seems to be important at the edges of dense clouds where the stellar radiationfield is particularly active (Öberg et al. 2007). The $S_{\mathrm{e}}^{2}$ dependence of the sputtering yield strongly favors the existence of heavy-ions in the cosmic-ray distribution and, for small grains, cause sputtering to dominate over the photodesorption in most of the cloud. We note that the desorption rate produced by iron ions alone is comparable to the rate of the desorption spot heating obtained by Léger et al. (1985), which also includes the 


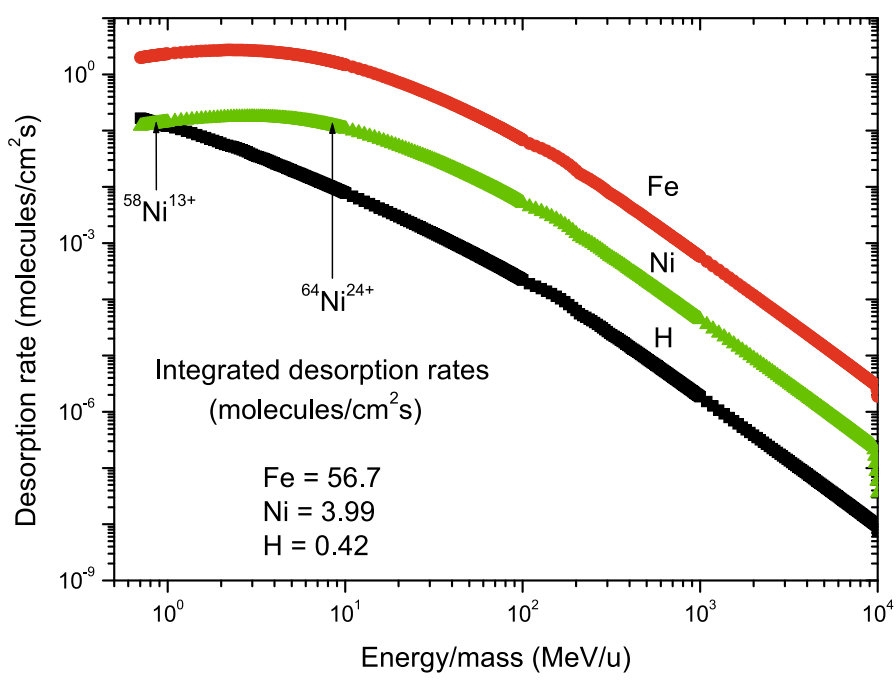

Fig. 8. Estimated desorption rates induced by $\mathrm{H}, \mathrm{Ni}$ and $\mathrm{Fe}$ ions as a function of their energy/mass.

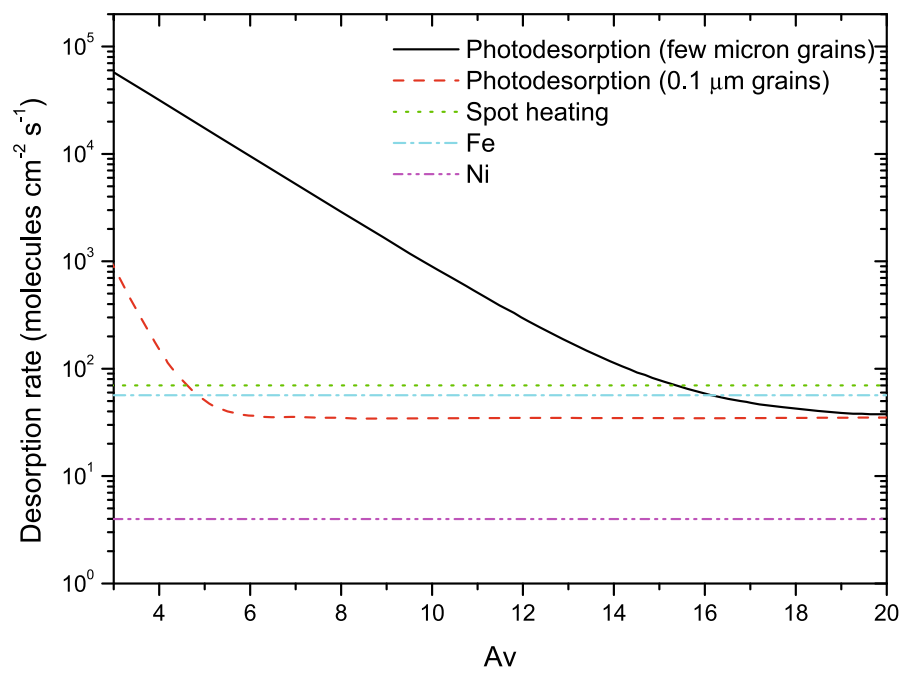

Fig. 9. Desorption rate of $\mathrm{CO}$ molecules as a function of visual extinctions. Photodesorption data for small and large grains are adopted from Öberg et al. (2007). The spot heating value was taken from Léger et al. (1985). The values presented for $\mathrm{Ni}$ and $\mathrm{Fe}$ are estimated from the results of the present work.

contribution of the other most abundant heavy-ion cosmic-ray species. This means that the true desorption rate produced by the contribution of heavy-ions in cosmic-rays may be even higher than the present estimations.

\section{Conclusions}

Condensed $\mathrm{CO}$ has been irradiated by $50 \mathrm{MeV}^{58} \mathrm{Ni}^{13+}$ and $537 \mathrm{MeV}{ }^{64} \mathrm{Ni}^{24+}$ ions. The new species produced in the matrix are essentially the same as those found after proton, photon, and electron irradiations. The destruction and formation cross-sections, as well as the sputtering yields have been determined. The radiochemical yield for $\mathrm{CO}$ molecular destruction/dissociation by heavy-ion bombardment is much higher than those produced by weakly ionizing projectiles. The measured sputtering yields scale with the squared electronic stopping power values, extending to higher $S_{\mathrm{e}}$ the results of Brown et al. (1984). Desorption induced by heavy-ion sputtering is proposed to be one of the two dominant processes leading to the presence of gas phase $\mathrm{CO}$ molecules in grains deep inside dense clouds and protoplanetary disks.

Acknowledgements. The authors acknowledge the agencies COFECUB (France) as well as CAPES, CNPq and FAPERJ (Brazil) for partial support. It is a pleasure to thank E. Balanzat, Th. Been, M. Ferry, I. Monnet and Y. NgonoRavache for technical assistance.

\section{References}

Baird, T. 1972, Carbon, 10, 723

Bennett, C. J., \& Kaiser, R. I. 2005, ApJ, 635, 1362

Bergin, E. A., Maret, S., van der Tak, F. F. S., et al. 2006, ApJ, 645, 369

Bringa, E. M., \& Johnson R.E. 2004, ApJ, 603, 159

Brown, W. L., Augustyniak, W. M., Marcantonio, K. J., et al. 1984, Nucl. Instr. Meth. B, 1, 307

Cermak, I., Forderer, M., Cermakova, I., et al. 1998, J. Chem. Phys., 108, 10129

Chiar, J. E., Adamson, A. J., Kerr, T. H., \& Whittet, D. C. B. 1995, ApJ, 455, 234

Chrisey, D. B., Boring J. W., Phipps, J. A., et al. 1986, Nucl. Instr. Meth. Phys. Res. B, 13, 360

Chrisey, D. B., Brown, W. L., \& Boring J. W. 1990, Surf. Sci., 225, 130

Cottin, H., Moore, M. H., \& Bénilan, Y. 2003, ApJ, 590, 874

Dartois, E. 2005, Space Sci. Rev., 119, 293

Dibben, M., Szczepanski, J., Wehlburg, C., \& Vala, M. 2000, J. Phys. Chem. A, 104,3584

Eiroa, C., \& Hodapp, K.-W. 1989, A\&A, 223, 271

Elsila, J., Allamandola, L. J., \& Sandford, S. A. 1997, ApJ, 479, 818

Farenzena, L. S., Martinez, R., Iza, P., et al. 2006, Int. J. Mass Spectrom., 251, 1 Freivogel, P., Grutter, M., Forney, D., \& Maier, J. P. 1997, Chem. Phys., 216, 401 Gerakines, P. A., \& Moore, M. H. 2001, Icarus, 154, 372

Gerakines, P. A., Schutte, W. A., Greenberg, J. M., \& van Dishoeck, E. F. 1995, A\&A 296, 810

Gerakines, P. A., Schutte, W. A., \& Ehrenfreund, P. 1996, A\&A, 312, 289

Gibb, E. L., Whittet, D. C. B., Boogert, A. C. A., \& Tielens, A. G. G. M. 2004, ApJS, 151, 35

Haring, R. A., Pedrys, R., Oostra, D. J., et al. 1984, Nucl. Instr. Meth. Phys. Res. $\mathrm{B}, 5,483$

Jacox, M. E., \& Milligan, D. E. 1974, Chem. Phys., 4, 45

Jamieson, C. S., Mebel, A. M., \& Kaiser, R. I. 2006, ApJS, 163, 184

Jiang, G. J., Person, W. B., \& Brown, K. G. 1975, J. Chem. Phys., 64, 1201

Karrer, R., Bochsler, P., Giammanco, C., et al. 2007, Space Sci. Rev., 130, 317

Loeffler, M. J., Baratta, G. A., Palumbo, M. E., Strazzulla, G., \& Baragiola, R. A. 2005, A\&A, 435, 587

Öberg, K. I., Fuchs, G. W., Awad, Z., et al. 2007, ApJ, 662, L23

Palumbo, M. E., Leto, P., Siringo, C., \& Trigilio C. 2008, ApJ, 685, 1033

Pilling, S., Seperuelo Duarte, E., da Silveira, E. F., et al. 2010, A\&A, 509, A87

Ponciano, C. R., Martinez, R., Farenzena, L. S., et al. 2006, J. Am. Mass Spectrom., 17, 1120

Ponciano, C. R., Martinez, R., Farenzena, L. S., et al. 2008, J. Mass Spectrom., 43, 1521

Pontoppidan, K. M., Fraser, H. J., Dartois, E., et al. 2003, A\&A, 408, 981

Prasad, S. S., \& Tarafdar, S. P. 1983, ApJ, 267, 603

Schmidt, R., Schoppmann C., Brandl, D., et al. 1991, Phys. Rev. B, 44, 2

Seperuelo Duarte, E., Boduch, P., Rothard, H., et al. 2009, A\&A, 502, 599

Shen, C. J., Greenberg, J. M., Schutte, W. A., \& van Dishoeck, E. F. 2004, A\&A, 415,203

Strazzulla, G., Leto, G., LaDelfa, S., Spinella, F., \& Gomis, O. 2005, Mem. S. A. It. Suppl., 6, 51

Szczepanski, J., Ekern, S., Chapo, C., \& Vala, M. 1996, Chem. Phys., 211, 359

Tielens, A. G. G. M., Tokunaga, A. T., Geballe, T. R., \& Baas, F. 1991, ApJ, 381, 181

Trottier, A., \& Brooks, L. B. 2004, ApJ, 612, 1214

Watson, W. P. 1975, Atomic and Molecular Physics and the Interstellar Matter, ed. R. Balian, P. Encrenaz, \& J. Lequeux (Amsterdam: North-Holland)

Weltner, W. Jr., Walsh, P. N., \& Angell, C. L. 1964, J. Chem. Phys., 40, 1299

Westley, M. S., Baragiola, R. A., Johnson, R. E., \& Baratta, G. A. 1995, Plan. Space Sci., 43, 1311

Whittet, D. C. B. 1992, Dust in the Galactic Environment, second edition (Institute of Physics Publishing)

Whittet, D. C. B., \& Duley, W. W. 1991, A\&AR, 2, 167

Willacy, K., \& Millar, T. J. 1998, MNRAS, 298, 562

Yamada, H., \& Person, W. B. 1964, J. Chem. Phys., 41, 2478

Young, J. S., Freier, P. S., Waddington, C. J., \& Brewster, N. R. 1981, ApJ, 246, 1014

Ziegler, J. F., \& Biersack, J. P. 2006, www. srim. org, version 2006.02 